\title{
Sensing properties of slag-based geopolymer composite with carbon fibers under compressive loading
}

\author{
Pavel Rovnaník ${ }^{1}$, Ivo Kusák ${ }^{2}$, Libor Topolá r $^{3}$, Pavel Schmid ${ }^{4}$ \\ Faculty of Civil Engineering, Brno University of Technology, Brno, Czech Republic \\ E-mail: ${ }^{1}$ rovnanik.p@vutbr.cz (corresponding author)
}

\begin{abstract}
Application of functional materials has become a new trend in the construction industry. This paper aims to study the electrical and self-sensing properties of slag-based geopolymer composite. In order to improve the electrical conductivity of the basic geopolymer mortar, carbon fibers in the amount of $0.5,1$ and $2 \%$ were added. The influence of fiber addition on the electrical properties was determined by impedance spectroscopy and microstructure was analyzed by means of mercury intrusion porosimetry and SEM. The sensing properties were tested under repeated compressive loading in the elastic range and finally under loading till failure. The electrical resistance decreased with the addition of carbon fibers but it caused a deterioration of the mechanical properties. The addition of fibers does not generally improve the sensing performance of the geopolymer composite, but the mixture with $2 \%$ of fibers appeared to be unsuitable for this purpose due to the low signal-to-noise ratio.
\end{abstract}

Keywords: geopolymer, carbon fibers, compression, sensing properties.

\section{Introduction}

Development of multifunctional materials is within the scope of many researchers in order to fulfill the demand for smart structures. Among these functionalities, strain, stress and damage sensing, heating control, absorption of electromagnetic waves or weight control of moving objects can be mentioned. A certain level of conductivity is necessary in order to achieve these functional properties of structural composites, and for this reason, conductive admixtures are usually added (Han, Yu, \& Ou, 2014). Despite the fact that much effort was already devoted to design, observations and utilization of electrically enhanced cement-based materials that can be used as smart materials, there does not exist any complex research focused on geopolymer materials enhanced in such a way.

The present study aims to investigate the self-sensing properties of slag-based geopolymer mortars with carbon fibers as conductive admixtures under compressive loading. The results are compared to plain geopolymer mortar without carbon fibers treated under the same conditions.

\section{Experimental part}

\section{Materials and sample preparation}

The geopolymer composite was composed of finely ground granulated blast furnace slag (Kotouč, CZ) and solid sodium silicate Susil MP 2.0 (Vodní sklo, CZ) which was used as an activator. The specific surface area of the slag was $395 \mathrm{~m}^{2} \mathrm{~kg}^{-1}$ and the chemical composition of both raw materials is given in Table 1. Quartz sand with a maximum grain size of $2.5 \mathrm{~mm}$ was used as aggregate. Carbon fibers (CF) Tenax ${ }^{\circledR}$-A HT C124 (Teijin Carbon) were used as conductive filler. The nominal length and diameter of the fibers were $3 \mathrm{~mm}$ and $7 \mu \mathrm{m}$, respectively, their tensile strength was $4000 \mathrm{MPa}$ and tensile modulus was $238 \mathrm{GPa}$. 2\% aqueous solution of Triton X-100 (Sigma-Aldrich) was used as a dispersing agent to improve wettability and homogenous dispersion of the fibers and silicone-based air detraining agent Lukosan S (Lučební závody, CZ) in the form of 1\% solution was applied to avoid the formation of bubbles.

Alkali-activated slag was prepared according to the following procedure. At first, carbon fibers were mixed with part of mixing water and Triton X-100. Sodium silicate activator was suspended and partially dissolved in water and mixed with a suspension of fibers. Then, slag and quartz aggregate were added and the mixture was stirred in a planetary mixer for about 5 min to prepare a fresh mortar. Finally, additional water and the solution of Lukosan $\mathrm{S}$ were

(C) 2019 Authors. Published by VGTU Press. This is an open-access article distributed under the terms of the Creative Commons Attribution (http://creativecommons.org/licenses/by/4.0/) License, which permits unrestricted use, distribution, and reproduction in any medium, provided the original author and source are credited. 
added. The activator dosage was $20 \mathrm{wt} . \%$ with respect to the slag mass and the aggregate/slag ratio was 3 . Carbon fibers were added in the amount of $0.5 ; 1.0$ and $2.0 \mathrm{wt} . \%$ with respect to the slag mass. The composition of the mixtures is presented in Table 2.

The cubic specimens having dimensions of $100 \times 100 \times 100 \mathrm{~mm}$ with embedded gauze electrodes were prepared for the measurement of sensing properties. The electrodes were made of $1 \mathrm{~mm}$ thick copper wires and mesh size of $2.5 \mathrm{~mm}$. Dimensions of the electrodes were $80 \times 120 \mathrm{~mm}$ and the span between them was $40 \mathrm{~mm}$. Impedance spectroscopy characteristics were measured on the $40 \times 40 \times 160 \mathrm{~mm}$ prismatic specimens. After $24 \mathrm{~h}$ the hardened specimens were immersed in a water bath at $20^{\circ} \mathrm{C}$ for another 27 days. The cubes for the measurement of sensing properties were stored at ambient conditions for 30 days before testing in order to reach moisture equilibrium.

Table 1. Chemical composition of granulated blast furnace slag and SUSIL MP $2.0(\%)$

\begin{tabular}{|l|c|c|c|c|c|c|c|c|c|}
\hline & $\mathrm{SiO}_{2}$ & $\mathrm{Al}_{2} \mathrm{O}_{3}$ & $\mathrm{Fe}_{2} \mathrm{O}_{3}$ & $\mathrm{CaO}$ & $\mathrm{MgO}$ & $\mathrm{TiO}_{2}$ & $\mathrm{Na}_{2} \mathrm{O}$ & $\mathrm{MnO}^{2}$ & $\mathrm{SO}_{3}$ \\
\hline Slag & 36.72 & 8.54 & 0.10 & 39.80 & 9.93 & 0.33 & - & 0.24 & 1.01 \\
\hline SUSIL & 25.03 & - & - & - & - & - & 12.98 & - & - \\
\hline
\end{tabular}

Table 2. Mixture proportions

\begin{tabular}{|l|c|c|c|c|}
\hline & CF 0 & CF 0.5 & CF 1 & CF 2 \\
\hline Slag $(\mathrm{g})$ & 600 & 600 & 600 & 600 \\
\hline SUSIL $(\mathrm{g})$ & 120 & 120 & 120 & 120 \\
\hline Quartz sand $(\mathrm{g})$ & 1800 & 1800 & 1800 & 12 \\
\hline Carbon fibers $(\mathrm{g})$ & - & 3 & 6 & 7 \\
\hline $2 \%$ Triton X-100 $(\mathrm{g})$ & - & 7 & 7 & 7 \\
\hline $1 \%$ Lukosan S $(\mathrm{g})$ & - & 7 & 7 & 240 \\
\hline Water $(\mathrm{g})$ & 240 & 226 & 235 & 72 \\
\hline
\end{tabular}

\section{Testing methods}

Prepared prismatic samples were characterized by impedance spectroscopy in the range of $40 \mathrm{~Hz}$ to $1 \mathrm{MHz}$ using sinusoidal signal generator Agilent 33220A and dual-channel oscilloscope Agilent 54645A. The output voltage of the signal generator was $5.5 \mathrm{~V}$. Input values of electrical capacity and resistance of oscilloscope were $13 \mathrm{pF}$ and $1 \mathrm{M} \Omega$, respectively. In order to perform impedance analysis, the prismatic specimens were placed between parallel brass electrodes $(30 \times 100 \mathrm{~mm})$ with the distance of $40 \mathrm{~mm}$.

Measurement of sensing properties during compressive loading was carried out on a hydraulic testing machine. The cubic specimens were loaded perpendicular to the plane of the $\mathrm{Cu}$-electrodes. In the experiment, cyclic loading and releasing of the samples was performed linearly with loading rate $400 \mathrm{~N} \mathrm{~s}^{-1}$ and in the range $5-50 \mathrm{kN}$. In the second experiment, these cubes were loaded linearly with loading rate $200 \mathrm{~N} \mathrm{~s}^{-1}$ till failure. The measurement of electrical resistance during loading was performed in AC mode with the frequency of $1 \mathrm{kHz}$ using a two-probe method. A sinusoidal signal generator Agilent 33220A and two multimeters Agilent 34410A were used for the measurement of electrical resistance. The adjusted signal voltage was $5 \mathrm{~V}$. The electrical current was calculated from the voltage measured on one of the voltmeters and the reference resistance $R$ which was exactly $6796 \Omega$. The electrical resistance of the measured sample was computed from the electric current flowing through the resistance $R$ and the voltage that was measured separately on the test sample using Ohm's law and taking into account the internal resistance of the voltmeter.

Acoustic emission method was used to monitor the events associated mainly with the crack formation during monotonous compressive loading till failure. The guard sensors eliminated that is generated from outside the area of interest. In this work, three acoustic MIDI emission sensors (type IDK-09, DAKEL, CZ) were used, all having identical frequency range and being attached to the surface by beeswax.

Porosity was measured by means of mercury intrusion porosimetry (MIP) analysis, which was conducted on cut samples using a Micromeritics Poresizer 9310 porosimeter. This device can generate a maximum pressure of $207 \mathrm{MPa}$ and can evaluate a theoretical pore diameter of $0.006 \mu \mathrm{m}$. The morphology of the microstructure and was analyzed using a TESCAN MIRA3 XMU scanning electron microscope in SE mode. The experiments were carried out on dried samples that were sputtered with gold using Quorum Q150R ES equipment. 


\section{Results and discussion}

\section{Electrical and sensing properties}

Electrical resistance of the geopolymer composites was analyzed with respect to the frequency of AC source (Figure 1). Generally, the resistance decreased with both increasing frequency and dosage of carbon fibers. There is a significant peak located around $1 \mathrm{kHz}$ in the curve measured for the reference mixture and this feature can also be observed as a small plateau for the mixture with 0.5 and $1 \%$ of carbon fibers. With higher amounts of fibers, a significant decrease in the resistance can be observed at a frequency around $1 \mathrm{kHz}$. The differences in resistance curves are clearly visible up to $200 \mathrm{kHz}$. Above this frequency, the resistance of all samples fluctuate and the curves overlap. Since a high difference in electrical resistance between the mixtures was achieved at approximately $1 \mathrm{kHz}$ and this frequency is also high enough to avoid polarization effect, it was used for the measurement of sensing properties.

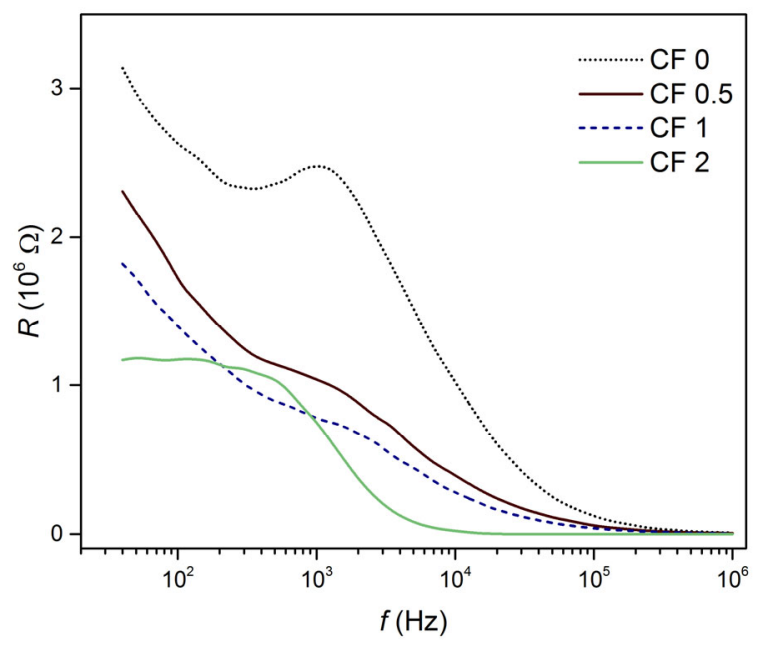

Figure 1. Electrical resistance of geopolymer composites with $0-2 \%$ of carbon fibers in the frequency range $40 \mathrm{~Hz}-1 \mathrm{MHz}$

Self-sensing properties of building materials stem from the change of conductive network inside composites, so the change in resistivity is able to characterize the sensing behavior. For these purposes, the fractional change in resistivity $(F C R)$ is used as a relative measure to describe self-sensing properties under different loading conditions. It can be calculated as follows:

$$
\operatorname{FCR}(\%)=\frac{R-R_{0}}{R_{0}} \cdot 100,
$$

where $R$ is electrical resistance and $R_{0}$ is the initial electrical resistance. The initial resistance of slag geopolymer decreased with increasing content of carbon fibers (Table 3 ).

Table 3. Initial electrical resistance of geopolymer composites

\begin{tabular}{|c|c|c|c|c|}
\hline & CF 0 & CF 0.5 & CF 1 & CF 2 \\
\hline$R_{0}(\Omega)$ & 18604 & 9187 & 4450 & 1367 \\
\hline
\end{tabular}

In order to compare the self-sensing properties of alkali-activated slag and cement mortars, cubic specimens with embedded $\mathrm{Cu}$-electrodes were subjected to repeated compressive loading at a fixed maximum of $5 \mathrm{MPa}$. This range fits into the elastic part of loading and does not cause any irreversible changes in microstructure. Totally ten loading cycles were accomplished in order to collect enough data of electrical resistance. The curves drawn in Figure 2 show the response of electrical properties, which are expressed as fractional change in resistivity, to the applied compressive load. As the compressive stress increases the electrical resistance decreases, which is in accordance with other studies reported for the cement based composites with conductive filler (Wen \& Chung, 2001, 2007; Cao, Wen, \& Chung, 2001; Li, Wang, \& Zhao, 2007). During compressive loading, the resistance decreased due to the healing of microcracks and defects formed by drying shrinkage. During unloading, it increased due to defect aggravation.

Plain geopolymer mortar without fibers showed the fractional change in resistivity of $2.1 \%$ during repeated loading and the baseline signal was very stable for selected conditions. Although carbon fibers decrease the resistivity of the geopolymer composite, self-sensing properties of samples with 0.5 and $1 \%$ of fibers appeared to be similar to those 
observed for the reference mixture. The baseline signal of these two composites continuously increased probably due to some kind of irreversible damage. On the other hand, the composite with $2 \%$ of carbon fibers showed a very bad sensing ability because of the very low signal-to-noise ratio.

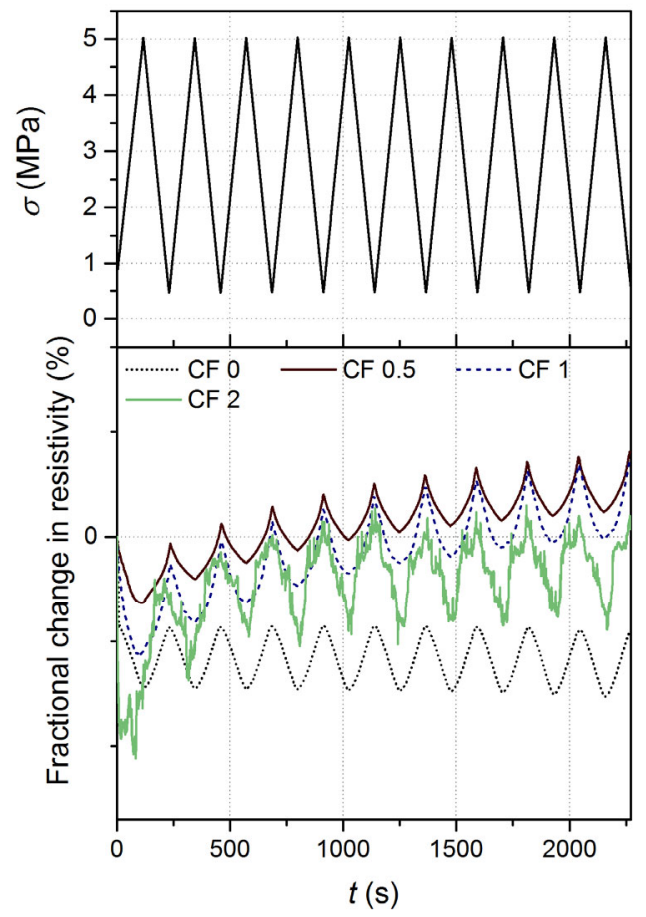

Figure 2. Fractional change in resistivity of geopolymer composites during repeated compressive loading

Fractional change in resistivity recorded during monotonous compressive loading showed extraordinary behavior (Figure 3). At first, the resistance linearly decreased but then it increased again and reached a local maximum for the samples with no or $0.5 \%$ of fibers. Then, it gradually decreased up to failure, at which it increased abruptly. Such behavior is caused by the formation of some preliminary defects under compression causing an opening of microcracks and partial destruction of conductive routes which are partially reconstructed at higher loads (Rovnanik, Kusák, Bayer, Schmid, \& Fiala, 2019). However, in the case of higher fiber portions, no further decrease in resistance was observed and the fractional change in resistivity increased till failure. Especially, in the case of CF 2 mixture, the fractional change in resistivity increased by $252 \%$ until the maximum of compressive stress was reached. High dosage of fibers caused a deterioration of the mechanical properties which can be attributed mainly to the problems with good dispersion of fibers and consequent increase in porosity. The addition of carbon fibers caused a significant decrease in compressive strength that can be estimated as maximum stress reached during compressive loading (Figure 3 ).

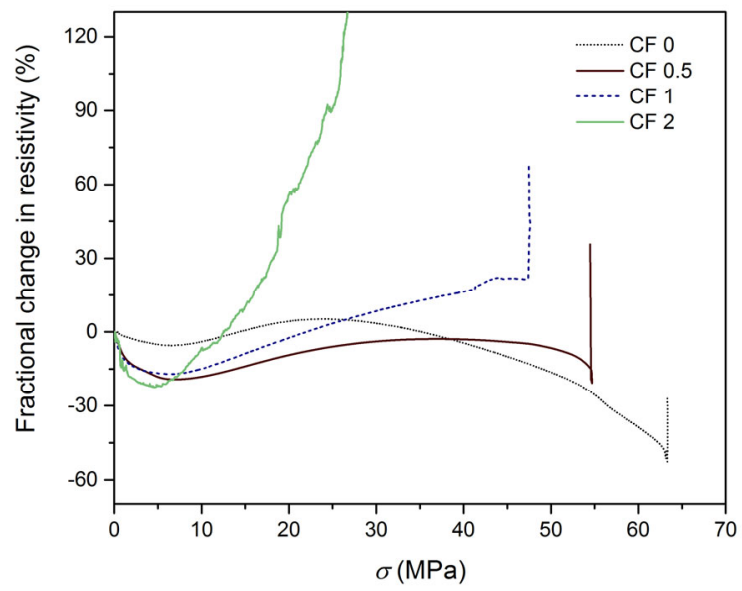

Figure 3. Fractional change in resistivity of geopolymer composites during compressive loading till failure 


\section{Acoustic emission}

The acoustic emission (AE) method is considered to be a "passive" non-destructive technique because it identifies defects while they are being developed during the test. This technique has quite a unique ability to detect crack formation and propagation occurring not only on the surface but also deep inside the material. To detect defects formation, we focused on a number of signals overshooting a pre-set threshold level. The cumulative number of AE signals versus compressive stress is presented in Figure 4.

The total number of AE signals recorded for the geopolymer composites with carbon fibers are very similar but these are 2.5 times larger than for the reference geopolymer. Another aspect is that with the addition of fibers a large number of AE signals was already detected in the very beginning of loading and this high level of events remained during the whole test. Acoustic emission measurement proved the initialization of the damage which corresponds to the primary increase on the fractional change in the resistivity curve. However, such formation of defects was more pronounced for a mixture containing fibers and caused more rapid deterioration of the mechanical properties.

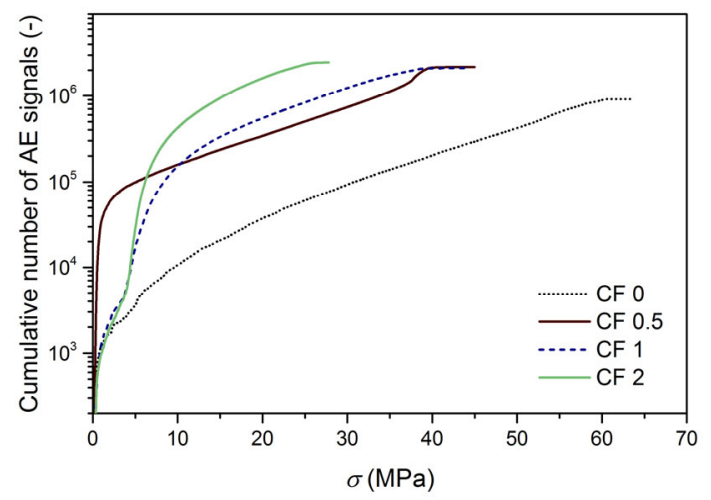

Figure 4. Cumulative number of recorded AE signals versus compressive stress

\section{Microstructure}

Pore distribution in the geopolymer composites analyzed by MIP is presented in Figure 5 . The total intruded volume increased with the addition of carbon fibers. Most of the volume was generated by capillary pores between 1$10 \mu \mathrm{m}$ and in the case of CF 2 mixture also by larger pores. This is also reflected in the drop of compressive strength when carbon fibers were added to the geopolymer mortar.

The distribution of fibers in the geopolymer matrix and the contact of fibers with the binder was investigated by scanning electron microscopy on the fracture surface of the prismatic specimens. Figure 6 shows that there is rather good contact with the matrix without any significant gap but the bond between the fiber and the matrix is very weak. This fact is caused by the nonpolar character of the carbon fiber which does not adhere well to the polar aluminosilicate structure of the geopolymer. As a result, the fibers do not break during fracture but they are rather pulled out of the matrix leaving there cylindrical voids.

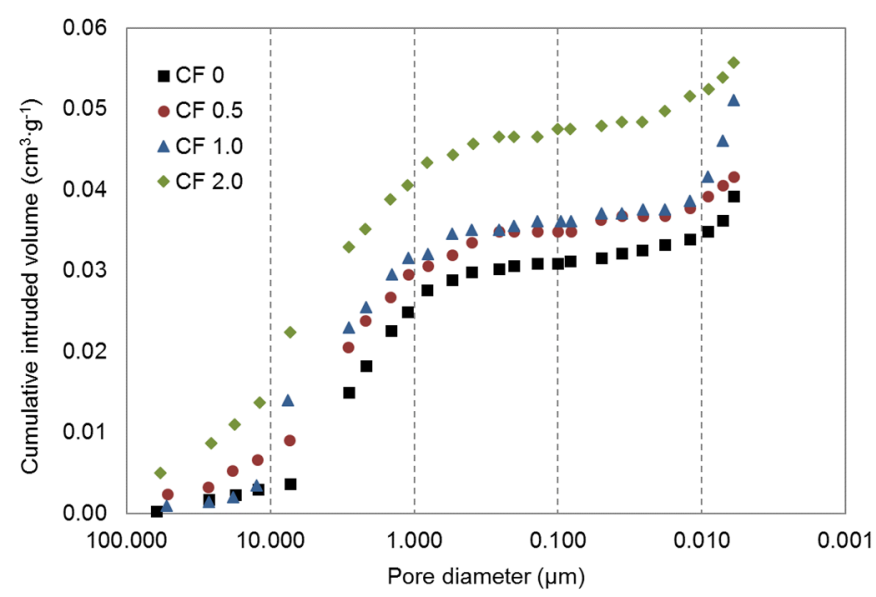

Figure 5. Cumulative pore distribution measured by MIP 


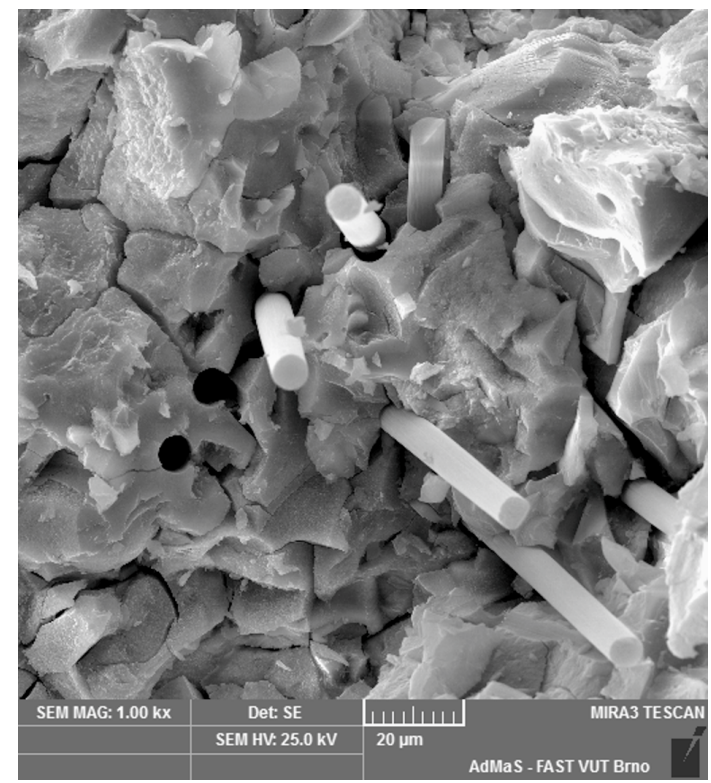

a)

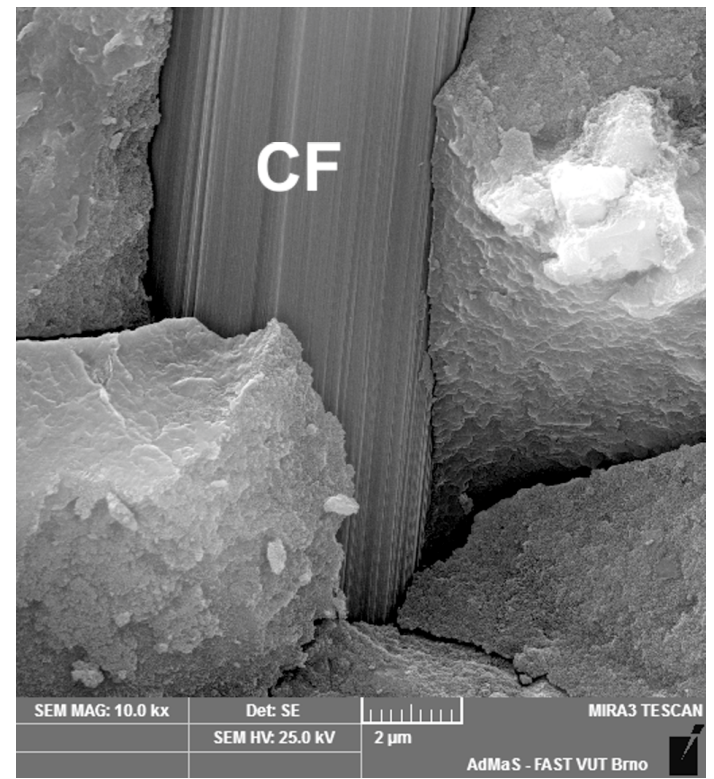

b)

Figure 6. SEM micrographs of the carbon fibers embedded in the geopolymer matrix: a) overview image; b) detail of carbon fiber

\section{Conclusions}

In this paper, electrical and self-sensing properties under compression of geopolymer composites based on blast furnace slag with three different amounts of carbon fibers were investigated. The properties were compared with reference geopolymer mortar without fibers. The experimental results have led to the following conclusions:

- Addition of carbon fibers to the slag based geopolymer mortar leads to a considerable decrease in the electrical resistance but causes the increase in porosity and consequent deterioration of the mechanical properties.

- Self-sensing properties under repeated compressive loading can be observed for all mixtures, however, the addition of fibers does not improve sensing properties of AAS mortar.

- After an initial decrease of FCR, the composites with carbon fibers showed a permanent increase of FCR during repeated loading, which is associated with a microcrack formation essential damage of the geopolymer structure. This effect is also supported by AE measurements.

- The sensing properties of the composite with up to $1 \%$ of carbon fibers at low compressive loads are quite similar, but the mixture with $2 \%$ of fibers appeared to be not suitable for the self-sensing applications because of a bad mechanical performance and low signal-to-noise ratio.

\section{Acknowledgements}

This work was supported by the Czech Science Foundation (grant number 19-11516S); and the Ministry of Education, Youth and Sport of the Czech Republic under the "National Sustainability Programme I" (grant number LO1408).

\section{References}

Cao, J., Wen, S., \& Chung, D. D. L. (2001). Defect dynamics and damage of cement-based materials, studied by electrical resistance measurement. Journal of Material Science, 36(18), 4351-4360. https://doi.org/10.1023/A:1017901929264

Han, B., Yu, X., \& Ou, J. (2014). Self-sensing concrete in smart structures. Oxford: Butterworth-Heinemann.

Li, G. Y., Wang, P. M., \& Zhao, X. (2007). Pressure-sensitive properties and microstructure of carbon nanotube reinforced cement composites. Cement and Concrete Composites, 29(5), 377-382. https://doi.org/10.1016/j.cemconcomp.2006.12.011

Rovnaník, P., Kusák, I., Bayer, P., Schmid, P., \& Fiala, L. (2019). Comparison of electrical and self-sensing properties of Portland cement and alkali-activated slag mortars. Cement and Concrete Research, 118, 84-91. https://doi.org/10.1016/j.cemconres.2019.02.009

Wen, S., \& Chung, D. D. L. (2001). Electric polarization in carbon fiber-reinforced cement. Cement and Concrete Research, 31(1), 141-147. https://doi.org/10.1016/S0008-8846(00)00382-3

Wen, S., \& Chung, D. D. L. (2007). Electrical-resistance-based damage self-sensing in carbon fiber reinforced cement. Carbon, 45(4), 710-716. https://doi.org/10.1016/j.carbon.2006.11.029 